\title{
THE SYSTEM APPROACHES IN RELATION TO ANIMAL PRODUCTION
}

A. S. Tabana

Faculty of Agriculture, South Valley University, Qena, Egypt

\section{INTRODUCTION}

Failure of livestock development reflects the rejection of technical innovations by small scale farmers which primarily introduced throughout development project or programs. Animal in small scale farming systems are just one components of the farm system. A new technical innovation (e.g. in relation to animal feeding), that would maximize the profit from the animals present on such farms, could at the same time ask extra labor input. The extra labor input for this new activity would result a lower labor availability for other farm activities (e.g. for activities related to crop production), resulting in lower profits from these activities. The final result seen over the whole farm system, could well be worse than before the introduction or application of the new innovation in one of its components.

Similarly, a crop specialists might be tempted to improve the crop component in direction that maximizes the proportion of human food (e.g. the number of grains per plant) and reduces the proportion of by-products (e.g. straw) on which the animal are fed or which are used for fuel or construction purposes.

The divergence between initial expectations of innovation to separate components of the farm system and actual results from them was also often due to the mistaken assessment of the role of an animal in a farming system. Many Egyptian scientists are looking at a traditional milk production system and observing the single Baladi cattle and buffalo cows producing a very low milk yield, may understandably consider that surely a better cow can be provided. This point of view has often been the starting point for a selection programme, a cross breeding programme, the importation of exotic breeds like Friesian, and even the introduction of technologies like artificial insemination in the traditional production systems. Such innovation would results more efficient cow that genetically capable for higher milk yield and also larger in size.

It immediately suggests that any increase in milk production is likely to involve an increase in the feed supply. This point is not necessarily considered in detail by the animal breeder, particularly if the feed comes from other parts of the farm or from byproducts of crop production. Additionally, an animal scientist may try to improve an agricultural system by improving the animal component, without realizing that the role of the animal not just the milk production. The animal may also carry out cultivation needed for crop production and produce manure for fertilizer or fuel. Also, animal has to live and produce or perform in a climatic environment (including adoption to local pests, parasites and water supply) within which is closely adapted or improved. Above all, be able to live on the available feed supply, much of which may be derived from crop by-products.

Issued by The Egyptian Society of Animal Production 
Other extreme example, where intensive livestock systems are widely practiced in the developed country. The industrialized livestock farming has also ignored aspects beyond the specific technological point of view, and this has led to environmental (e.g. excess manure production and acidification because of ammonia losses) as well as social problems (e.g. awful smell \& product quality) .

\section{A Systems approach \\ Problem Perceived Approach}

The starting point for scientific research is the formulation of a perceived problem into a general problem statement which in turn leads to the formulation of one or more research hypotheses. On the basis of the general problem statement and the research hypotheses derived specific research goal can be formulated. The process from formulation of the initial problem statement and leading to the definition of specific research goals can be seen as the most important aspect of scientific research because it determine what is investigated, why it is investigated, how it is investigated and how the results will be interpreted. The crux therefore is the approach of the problem perceived, and as a result, the formulation of the general problem statement and the research hypotheses derived.

\section{Reductionism or mechanistic Approach (Disciplinary Studies Approach)}

For long time problem situations in relations to complex systems in which everything seemed to be related to everything, was to consider only one aspect of the problem (e.g. only nutritional aspect, only a physiological aspect, only breeding aspect) and to study those aspects separately so called disciplinary studies. Thus, systems were reduced to their separate disciplinary parts, without considering why these parts were to be found in particular context. Three major phases can be distinguished in this approach towards a problem situation.

- a complex problem is reduced to disciplinary parts or processes.

- Gathering in-depth disciplinary knowledge on these parts or processes

- Combine the knowledge on different parts of the processes to solve a complex problem (this step is normally not even made and when it is, often called a multidisciplinary or interdisciplinary or integrated approach).

This approach involves two ways of thinking: 1) Reductionism; and 2) Determinism. Reductionism refers to the in-depth knowledge on separate parts, determinism expresses the idea that understanding the whole object of study, or the whole complex problem, can be based on the combined disciplinary knowledge. The reductionism approach therefore leads to Know-how (or knowledge) about specific system component.

\section{The Holistic approach}

This approach argues that when a complex system consisting of many related components is broken down, it loses its essential characteristics that results from the various relations between the components that make up the system. Moreover, also the specific interaction of the system with its environment or its context, is ignored. 
Comparing the holistic approach with the reductionism approach, it reverses the three steps mentioned before.

- Identify the enclosing whole of which the object of interest is a subsystem, its relation to other components (subsystem) in the enclosing whole and the context of the whole system.

- Study the behavior or the characteristics of enclosing whole.

- Study the behavior or the characteristics of the object of interest in terms of its function within the enclosing whole.

The three steps describe a way of thinking called holism, it mean the relation between the elements or subsystems of the whole system and the placing of the whole system in its (ecological, economic and social) context determines the behavior of the whole system. therefor, the holistic approach leads to know-why (or understanding) instead of know-how expressed in the reductionism approach.

In agriculture research, and animal science, a reductionism approach has for a long time determined the way of thinking. The main focus was to increase individual animal and crop production. Major achievements of a reductionism approach are, for example, a specialized knowledge of animal metabolism, the increase of animal product per animal, the increase in growth rate, artificial insemination, embryo-transfer technology, et cetera. However, research according to the reductionism approach has been very helpful in increasing knowledge on specific technical, environmental or economic insights.

\section{The farming system research}

Many farmers have not been able to benefit from new technology developed by agriculture scientists. The reason why the impact of the technology differs so widely between farmers. To formulate it in a simple way, farmers have been missed out either because the technology did not address their most important needs and constraints, because the resources needed for innovation were not available to the farmers or because it implied changes in the collection of resources that conflicted with their other activities.

Over the last decade, agricultural researchers have been aware of the need to design the technologies that is more appropriate to the needs and constraints of small farmers. The development of farming system research (FSR) methodology in which there is a close cooperation between technical and social scientists. Rather than replacement or a new discipline. However, FSR is primarily a research approach, and not a development strategy, although its results may have implications for development planning.

FSR as approach has its basic ideas in common with system approach, i.e. considering system components in their context, rather than isolated from their context. FSR views the whole farm as a system and attempts to study a complex of factors that are under the households control. It id interdisciplinary and farmer-oriented in nature and integrates research and development strategies. FSR implies a stepwise research approach as following: characterizing existing farming systems, identifying constraints and opportunities, designing and executing on-farm and on-station research, and evaluating and implementing the results. The testing of technology should not only take place in research stations but mainly on farmer fields, and ultimately by farmers themselves. 


\section{The following figure outlining a classical FSR methodology}

The first step, the diagnosis, more precisely it is the first step within the diagnostic phase, together with the secondary data (i.e. data from literature, local authorities) that are collected and information obtained through Rapid Rural Appraisal Survey ( an informal survey in which existing information is gathered from the farmers and the area it self, a collection of background information also known as a Sondeo) a holistic approach makes it possible to classify agriculture production system and consumption systems (market structure) and to assess why these system occur in their specific ecological, economic and social context.

The next steps that is selecting FSR sites (areas, villages, or farming systems that will be studied in depth) and identifying constraints and opportunities of these selected sites, will therefore be based on a systems approach to the problem situation in that region, the problem situation that initiated a research program in the first place.

The classical FSR has been conducted mainly by crop researchers, and its established methodology focuses on cropping systems. Animal scientists have lagged behind crop scientists using the same tools. In this capacity, data collection is a major constraint in livestock systems, The livestock on-farm studies in smallholder farming systems, whether farm surveys or on-farm experiments are complicated because:

1) livestock are a valuable asset, so farmers are reluctant to accept interventions involving their animals

2) culture and tradition play a large role in livestock keeping

3) livestock are mobile and thus difficult to measure and control

4) the life-cycle of the livestock is long and complicated

5 ) in the small farm setting, the number of animal in particular ruminants in a specific category is always extremely limited.

The livestock research from a system prospective is usually restricted to collecting masses of baseline data, in the mistaken belief that data gathering is always useful, or to on farm testing of new technologies without a proper evaluation of already existing and used technologies. Much of the information obtained is stored in internal reports or other hardly accessible documents, or lies completely unused because the lack of suitable analysis. Added to this, their is little consistency in how the data are recorded, analyzed and presented. 


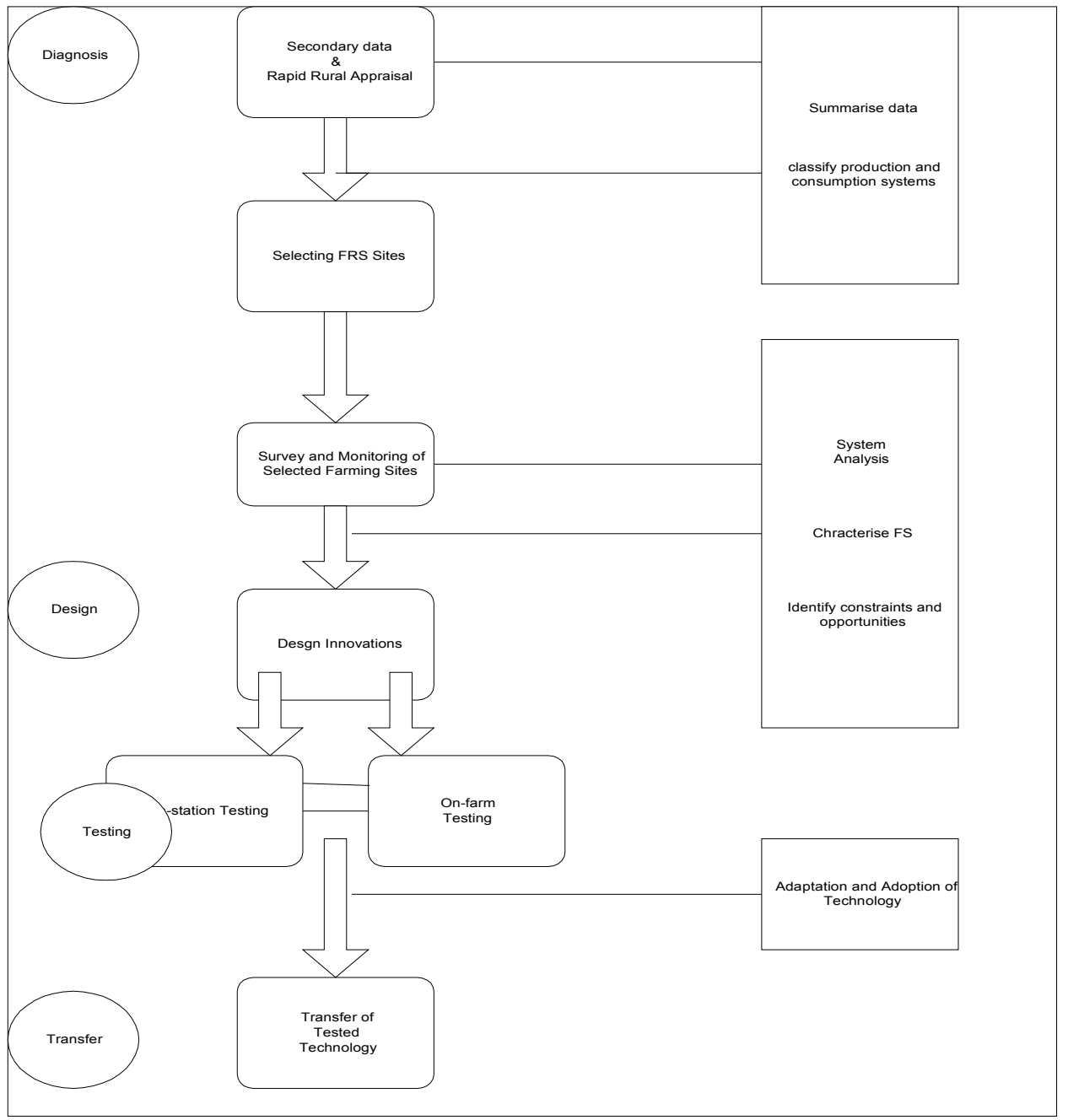

\section{REFERENCES}

Bowman, P.J., D.A. Wysel, D.G. Fowler and D.H. White, 1989. Evaluation of a new technology when applied to sheep production systems: part I- Model description. Agriculture Systems 29:35-47.

Congleton, W.R.Jr., 1984.Dynamic model for combined simulation of dairy management strategies. J. Dairy Sci. 67:644-660.

Hathout, M.K., S.A. El-Saadany, A.S. Tabana, M.M. Ismail and I. M. Gomaa, 1996. Features of dairy farming under crop-livestock mixed system in the Delta region, 
Egypt.Proceeding of international symposium on Buffalo Resources and Production Systems. Cairo, Egypt, Oct. 14-17, pp. 30-40

Kearl, L.C., 1982. Nutrient requirements of ruminants in developing countries. International Feedstuff Institute, Utah State Institute, Logan, $381 \mathrm{pp}$

Mainland, D.D., 1994. A Decision Support System for Dairy Farmers and advisors. Agriculture Systems, 45, 217-231

Moll, H.A.J., 1993. On-farm livestock research: A framework for planning. Goat production systems in the humid tropics. Proceedings of an international workshop at the Obafemi Awolowo University, lle-lfe, Nigeria, 6-9 July 1992. Pudoc Scientific Publishers, Wageningen.

Olney, G.R. and G.J. Kirk, 1989. A management model that helps increase profit on western Australian dairy farms. Agriculture Systems 30:367-379.

Pearson, R.E. and R.H. Miller, 1981. Economic definition of total performance, breeding goals, and breeding values for dairy cattle. J. Dairy Sci., 64, 857-69.

Schiere, J.B. and J. De Wit, 1995. Feeding urea ammonia treated rice straw in the tropics. II: Assumptions on nutritive value and their validity for least cost ration formulation. Anim. Feed Science and Technology, 51:45-63.

Schiere, J.B., and A.J.Nell, 1993. Feeding of urea treated straw in the tropics. I. A review of its technical principles and economics. Anim. Feed Sci. and Tech., 43:135-147.

Šrensen, J.T., 1989. A model simulating the production of dual purpose replacement heifers. Agriculture Systems 30:15-34.

Stott, A. W. and Elston, D.A., 1991. Interpretation of linear profit function in the presence of correlated predictors, with application to decision support in a dairy enterprise.

Tabana, A.S., 1998. Farmer response to the introduction of new extension packages in Ashmoun district. Serial document number 4, Dairy Systems Analysis Unit, Animal Production Research Institute, Cairo, Egypt.

Tabana, A.S.,2000. Development of a decision support system for individual dairy farms in mixed irrigated dairy farming systems in lower Egypt. Ph.D. Thesis, Wageningen, The Netherlands.

Tabana, A.S., H. van keulen, S. Tamminga and I. Gomaa, 2000. Animal Production System in Egypt: Their roles, classification, description and potential contribution to development. Proceeding for the 3rd Africa conference on Animal Agriculture, joint with the $11^{\text {th }}$ conference of the Egyptian Society of animal production. Alexandria, November 6-9, 2000.

Tabana, A.S., K. Suradisastra, M.C. Mojica and N.P. Sing, 1995. Development oriented study of the upland farmers in Desea Cijambe, West Java, Indonesia. Series Documents No 45; ICRA, Wageningen, The Netherlands.

Tigges, R.J., R.E. Pearson and W.E. Vinson, 1984. Use of dairy herd improvement variables to predict lifetime profitability. J. Dairy Sci, 67, 180-4. 